\title{
The good, the bad and the wiki: Evaluating student-generated content for collaborative learning
}

\section{Steve Wheeler, Peter Yeomans and Dawn Wheeler}

Steve Wheeler is a Senior Lecturer in education and ICT, Peter Yeomans is a Lecturer in Education and ICT, and Dawn Wheeler is an Associate Lecturer in Literacy and ICT, all in the Faculty of Education at the University of Plymouth. Address for correspondence: Steve Wheeler, Faculty of Education, Isaac Foot Building, University of Plymouth, Drake Circus, Plymouth PL4 8AA, UK. Tel: 01752-232332; email: swheeler@plymouth.ac.uk

\begin{abstract}
This paper explores the potential for wiki-type open architecture software to promote and support collaborative learning through the use of studentcreated content. It delineates some of the affordances and constraints of wiki software as an open architecture that has the potential to facilitate collaborative learning through community-focused enquiry. It seeks to promote debate in this key area of development, and highlights some recent key contributions to the developing discourse on social software in what has been termed 'the architecture of participation'.
\end{abstract}

\section{Introduction}

It has never been more imperative for educators to understand how to adapt new technologies and software into real teaching contexts (Wheeler, 2001). Interactive digital technologies are playing an increasingly important part in all sectors of education, and few educational providers are without an e-learning strategy. Currently, many teachers are seeking to establish interactive environments in which technology is used to support and enhance collaborative learning processes (Jonassen, Peck \& Wilson, 1999) while students tend to seek active engagement with others because they see it as both useful and satisfying (Horizon, 2007). For a growing number of teachers and students, social networking and social software are proving to be a fertile terrain within which communities of learning coalesce (Ebersbach, Glaser \& Heigl, 2006). There is evidence that user-created content software in particular encourages deeper engagement with learning through the act of authoring, simply because the awareness of an audience, no matter how virtual or tentative, encourages more thoughtful construction of writing (Jacobs, 2003).

There is also a growing trend toward student-led collaborative learning where teachers adopt a supportive role and become learning resources (Harden \& Crosby, 2000). Stu- 
dents are increasingly adopting new roles as producers, commentators and classifiers (Horizon, 2007), and are participating more in the personalised construction and organisation of their own knowledge (Jonassen et al, 1999) outside the traditional boundaries of education. This shift in emphasis toward social networking, although rooted in social constructivist theory, also has drivers in new technologies (Richardson, 2006) and a postmodernist belief that knowledge should be discursively constructed across a multiplicity of sites (Gale, 2003). Commentary on this phenomenon can be traced back almost 4 decades.

\section{Funnels and webs}

Arguing for a deconstruction of education, Ivan Illich famously argued that an 'education web' approach should replace the traditional school system. In an ideal education web, itinerant scholars travel beyond the boundaries of traditional schools to share their expertise, make social connections and create new and informal knowledge structures:

The current search for new educational funnels must be reversed into the search for their institutional inverse: educational webs which heighten the opportunity for each one to transform each moment of his living into one of learning, sharing, and caring. (Illich, 1970, p. 2)

Illich's radical 'deschooling' thesis was of course intensely criticised, first because it was overtly anarchistic, and second, as a pragmatic rebuttal. At its time of publication, and with learning technology still embryonic, any notion of an 'educational web' was considered not only impractical, but unattainable. Illich's ideas presaged the Web by several years, and it is only now, with the advent of the Internet and the profusion of pervasive mobile, wireless communication technologies, that we are able to witness first-hand the supplanting of Illich's 'funnels' with the informal 'webs' of itinerant students. A clear distinction can be made. Funnels are unidirectional, whereas webs grow exponentially in any and all directions their users choose to take. Through the use of hypermedia, formalised education delivery mirrors the connective matrix of the human brain, assuming an infinite number of rhizomatic forms (Deleuze \& Guattari, 1987). Further, the idealism of 'personalisation' may actually be realised for many students who are empowered to travel learning pathways of their own choosing within the digital terrain.

\section{Social networking}

Interaction and collaboration are increasingly being mediated through the social medium of web-based environments. Social networking spaces such as FaceBook, MySpace and YouTube afford students unprecedented opportunities to share their ideas, celebrate their creativity and receive immediate feedback from fellow networkers. Students across the globe are able to 'swarm together' (Rheingold, 2003), coalescing their activities within rich and dynamic social environments, rather than wandering aimlessly through a socially 'cold' digital wasteland (Wallace, 1999). Social networking compels learners to participate in the digital milieu and brings them back regularly to 
repeat productive and enjoyable experiences. These are very desirable attributes for educational materials to exhibit (Horizon, 2007).

As the social web continues to grow in scale and influence, students will enter new and previously unknown territory, and will begin to exploit the social dimensions that open before them. Virtual worlds such as Second Life, social tagging systems including Del.icio.us, and massively multiplayer online role-playing games will all contribute toward rich and dynamic collaborative experiences in education (Boulos \& Wheeler, 2007; de Freitas, 2006). To fully appreciate the role the social web will play in education, it is important to comprehend the concept of communities of practice.

\section{Communities of practice}

Communities of practice (Lave \& Wenger, 1991) serve the purpose of expanding knowledge and improving professional practice within a discrete specialism (Godwin-Jones, 2003). They may be organised as informal networks in which ideas are generated and exchanged (Stewart, 1996) comparable to the notions expressed by Illich. The use of easily accessible and quickly modifiable digital repositories may be vital to their success. Communities of practice should be considered important to education if one subscribes to Wenger's theory that acquisition of knowledge relies on the interaction between individual experiences and socially defined knowledge structures (Wenger, 2000). For many learners, membership of a community may be particularly crucial, affording them the facility to return regularly to the grounding of a social network, regardless of their location. The social network provides opportunities for the individual learner to create sound and viable knowledge syntheses from fractured and inchoate information. The generation of viable ideas, sharing of common classes of problems and the mutual pursuit of solutions enables individuals to aim toward a common goal of knowledge creation (Owen, Grant, Sayers \& Facer, 2006).

\section{Wiki-'architecture of participation'}

Knowledge creation through user-created content is currently capturing the imagination of students and teachers alike, and one social software tool- the wiki-is developing quickly as a favourite in all sectors of education (Horizon, 2007). The word 'wiki' (from the Hawaiian wiki wiki) is translated as 'to hurry', and wikis certainly enable rapid and easy authoring direct to the Web. Wiki pages can be used by all to publish new content direct to the Web, including text, images and hyperlinks; to edit existing content; and also, because the wiki is fluid and open to all, to 'roll back' if necessary to previous versions through a 'page history' utility. Students can develop their own knowledge content with alacrity using a wiki and seldom need to study alone because of participation in a technologically mediated social space conducive to the formation of communities of practice (Boulos, Maramba \& Wheeler, 2006).

Wikis enable students to collaboratively generate, mix, edit and synthesise subjectspecific knowledge within a shared and openly accessible digital space. The combined knowledge of the group-dubbed 'the wisdom of the masses'-is assumed to be 
greater than that of the individual, and the group that creates the wiki space is the same group that reads it (Owen et al, 2006). While this 'architecture of participation' (O'Reilly, 2004) has obvious attractions to the digital generation, what is contentious is the extent to which lay-generation of digital artefacts is accurate and appropriate to professional education. Doubt also hangs over the concept of student created content and whether it will ever be legitimised by the traditional education establishment.

Patently, there is a sea of issues within which wiki activities are found to be afloat. Perhaps the most important issue for educators derives from the user generated nature of the wiki and the potential problems associated with it. There are no guarantees for accuracy and veracity on a wiki, although a recent survey conducted through the journal Nature found that Wikipedia, one of the most popular wiki knowledge repositories, is at least as accurate as Encyclopaedia Britannica (Terdiman, 2006). Wikis are susceptible to vandalism and malware (virus) attacks (Terdiman, 2006) so those moderating their use must be vigilant. Although the openness of wikis creates opportunities for the deliberate sabotage, Owen et al (2006) point out that there is often a critical mass of users who have sufficient ownership of the wiki to quickly intervene and clean up unwanted postings and recover the site. RSS (Really Simple Syndication) feeds alert community members to any changes that have been made to content, so that validation of the entries can be undertaken quickly and effectively. 'Roll-back' correction facilities can be used to restore the page to a previous condition if, for any reason, the additions need to be rejected.

\section{Some pedagogical applications}

A number of high-level thinking skills and socially rich activities could result from the use and management of wikis. A few teachers are already exploiting the potential of wikis to transform the learning experience into one in which student centred learning can be facilitated. The wiki may become a focal point of interest for developing communities of practice, within which they can store their treasure house of knowledge about their specific interests and learning. In classroom learning, teachers will need to encourage all members to contribute, thereby fostering a sense of community, but it is inevitable that some students will contribute more content than others. Social loafing is sometimes observed where the contribution rate for some students is disproportionate to others. However, providing all members are deemed to have contributed something within a defined period, teachers might adopt a laissez-faire attitude. Previous studies have shown that some students learn even when they do not directly contribute to a message board, which has been termed 'lurking' (Beaudoin, 2002).

Wikis offer appropriate environments within which students, who are separated geographically from one another, can develop social ties. Teachers may cause distributed groups to 'draw together' by encouraging each physically dislocated member to create a specific section or 'stub' on the wiki, so that others are then able to add to it over the life of a course of study. Individual students can be assigned the task of finding relevant 
and reliable websites they can hyperlink back to the main wiki. Each student can also be assigned a specific time period during which they have responsibility to 'patrol' the wiki to ensure it has not been sabotaged or defaced in some way.

\section{Folksonomies}

Students are able to tag particularly useful web resources within a highly visible space such as del.icio.us.com, thus alerting other students to their location and quality. This 'social tagging' replaces traditional, externally imposed hierarchies of categorisation (the taxonomy) with a process of content organisation reflecting the interest of the group, known as a 'folksonomy'. Arguably, such folksonomies provide a more fluid and accurate representation of the current needs and aspirations of the user group (Owen et al, 2006) which can change as group interests develop (Boulos et al, 2006). Further, the tagging of wiki pages makes their content more visible to a larger audience through search engine listings. Larger audiences often encourage students to be more accurate in their construction of wiki pages.

\section{Method}

Four groups of education students in the authors' own parent institution have been using open-content generation software for the past year as an integral part of their undergraduate teacher training studies $(n=35)$. Students were 1 st-, 2 nd- and 3rd-year undergraduates enrolled on the Bachelor of Education with Honours (B.Ed [Hons]) primary education programme. Ages ranged from 18 to 25 years, and there were two mature students. Each participated in this evaluative study voluntarily and all contributions were anonymised. Students used the wikis regularly during their classroom sessions as a space to store and edit the work from their research exercises, and as a forum for discussion. During teaching sessions students were invited via the integrated discussion board to post their views on their use of the wiki. Participants were also invited to complete a post-module questionnaire via email.

\section{Results}

As with any new technology or approach, the use of wikis in formalised education engenders issues and challenges for teachers. One of the first issues to address was the need to familiarise students with the concept of wikis and orienting them to the architecture of the software. Although comments were generally positive, there were limitations to effective use of the wiki. Some students reported confusion at the start of their first session, expressing uncertainty about what was required of them, and ambivalence regarding the potential of the wiki:

To begin with, this session was quite stressful and i feel we weren't voicing our ideas very well therefore it took a while to get started. However having organised what everyone was doing, I think it worked really well- it is simple to use and easy to find your way around. (2nd-year female undergraduate)

After a slow start with some confusion, we managed to compact our ideas and begin to see the potential the wikispace has. I think that, personally we can benefit from this and it will enhance our understanding ... . (2nd-year male undergraduate) 
The wiki activities did not suit the learning preferences of all students. One student expressed her concerns that the wiki was too unstructured and that although she enjoyed working on it, she required some boundaries in order to make sense of her learning:

... this was too open for me. I would need a little more structure and feel for where I'm going with this. it's enjoyable but I wouldn't be mad about this. (1st-year female undergraduate)

Students discovered that apportioning responsibilities to each individual enabled all to successfully collaborate in the construction of their knowledge repository. However, a potentially serious limitation is that although this strategy avoids conflict between competing contributors, it may isolate individual contributions, and students may read very little of the content created by their peers.

Another issue to emerge from the use of wikis in the classroom was the problem of ownership and intellectual property. In a similar fashion to academics, students tend to protect their ideas as their own work, and although happy to post their contributions to a wiki space for other group members to read, they are resistant to having their contributions altered or deleted by other group members. This seems to be less of a problem in user-created content sites such as Wikipedia, where contributors are relatively anonymous. In classroom contexts, where students are familiar with each other, ownership appears to be an issue. Comments from students in a discussion area attest to strong feelings:

I don't like the fact that it's anonymous. I want credit for what I have done. (2nd-year male undergraduate)

I think I will cry if anyone changes my page!!!: I do like Wiki though, its very useful. (1st-year female undergraduate)

If anyone changes my page, I'll kill them! Its [sic] odd I do feel a slight ownership to my page. (1st-year male undergraduate)

The limited capacity of the free wiki software also had a detrimental effect on multipleuser editing. When students attempted to add to shared pages there was occasional conflict, and the software was unable to cope with the simultaneous posting. Students reported their frustration on the discussion board:

It is very difficult to share a page, as sometimes it can get deleted which can be very annoying!!! (1st-year female undergraduate)

... anger, as every time you type something and someone else is on the page, it will just delete everything you do. I believe that if you decide what to put on the page before you start typing, this will solve a lot of arguments. (1st-year male undergraduate)

Using a shared area is fun but can be annoying when the work you have just typed gets wiped because someone else is editing the page at the same time!!!! We worked in two teams and there was definitely competition. (1st-year female undergraduate) 
Other issues emerged during the first few weeks of implementation including an observation that most students contributed to the wiki only when in class. Those who contributed outside class, usually did so in the late evenings, or over weekends, when they were not required to attend other classes. This is an issue identified by Ebersbach et al (2006) who suggest that if such tools are not integrated into regular routine, the result is that one or two people usually do the writing and others merely read.

Students tend to read only those pages to which they had contributed, which tend to negate the original objective of collaborative learning through content generation. In situations where content was jointly developed by small groups of students, more reading was undertaken across several pages.

Initially, students tended to copy items directly from sites such as Wikipedia, and paste them directly into the wiki pages, instead of creating hyperlinks to those sites. After several sessions, students learned to write their own commentaries and were encouraged by teaching staff to include images alongside their text, and other media such as movies and sounds. At times, however, 'design' issues tended to obfuscate the original aims of personal learning through research, with the awareness of a potential audience a consideration.

There were also several beneficial aspects to the wiki. Students were aware of an unseen audience and their comments reveal a strong desire to write accurate and relevant content to the wiki space:

It's scary the fact that anyone can look at what we have written. It's a great way to share ideas and information. (1st-year female)

It's interesting. It's amazing how anyone in the world has the potential to access what we ourselves have written. Sharing ideas gives a basis for discussion. (1st-year female)

Some reported that their writing skills had improved as a result of their use of the wiki in a collaborative context:

Writing on the wiki is a challenging activity which involves much more thought about the length and structure of sentences as it is able to be read by anyone. The exclusion of a spell check also provides more challenges of careful thinking. (1st-year male)

Students also reported that they were able to develop their critical thinking skills through the use of the shared spaces. A consideration of the work of other students in their groups and across groups which would not naturally meet appears to be a powerful catalyst:

I am now developing a healthy critical and analytical writing style thanks to the wiki. Looking at other people's opinions and findings has helped me to question what's in front of me .... . (1st-year male) 


\section{Recommendations and conclusion}

Students need to develop skills to ensure they are adequately equipped to participate fully in the knowledge-based economy of the $21^{\text {st }}$ century. These skills include knowing how to evaluate information critically; knowing how to work independently without close supervision and being creative (DfES, 2006). Wikis seem to provide the perfect tool for teachers to extend those skills for the students in their care.

Students may initially feel daunted by the prospect of 'writing to the Web', and may experience anxiety about receiving criticism from their peers and from an unseen web audience. Teachers could assuage these fears by developing students' confidence through the use of a practice simulation which is open only to the peer group, prior to using a live online wiki space. Students should also be fully apprised of the probability of their work being edited or extended by others, or even deleted if considered inaccurate or inappropriate. All contributors should be aware that editing of content is a natural and discursive feature of the wiki, and that collaborative learning requires negotiation of meaning and frank exchange of ideas. Students should understand that once the 'send' button has been pressed, the idea no longer belongs exclusively to the originator, but now becomes the property of the whole learning community. Wikis are always 'a work in progress', so the untidy nature of the pages should not be a prime consideration. Although design issues encourage readers to explore pages, content accuracy and relevancy should be prime considerations. Time might also be provided for students to discuss their feelings about participation and the social and pedagogical implications of user-created content. There are implications here for formalised assessment of learning. In future delivery of training programmes, the authors intend to pilot a scheme in which at least a part of the module assessment can be fulfilled through contributions to the wiki. At present, all assessment is conducted through the submission of written assignments. Transferring some assessment activities to a shared, collaborative space such as a wiki would raise a number of issues of quality, authenticity and plagiarism. The problem of equitable marking of individual work would also require further thought, given the shared and public nature of the wiki. There is also sufficient scope to investigate whether the use of wikis in other non-westernised cultures has similar affordances and constraints.

In summary, collaboration, rather than competition, should be emphasised as a key aim of any wiki-based activity. Students should also be encouraged to contribute to the wiki outside of classroom contact hours, and to share their thoughts, useful resources and discoveries as they generate them. When in class, wiki content creation should be an activity integrated into the fabric of lessons. Teachers should act as moderators rather than instructors, and may need to restrain themselves from direct action, in order to promote free and democratic development of content according to the principles embodied in the 'wisdom of the masses'.

As with many of the emerging Web 2.0 software applications, wikis have the potential to transform the learning experiences of students worldwide. The benefits appear to outweigh the limitations. For many learners, wikis will be particularly appealing, providing 
instant, any time-any place access to a dynamic and ever building digital repository of user-specific knowledge and a voice in a live community of practice. We may not be able to 'deschool society' in the manner envisioned by Illich, but wikis and other open source software may yet enable us to effect some transformational changes in education.

\section{References}

Beaudoin, M. F. (2002). Learning or lurking? Tracking the invisible student. Internet and Higher Education, 5, 147-155.

Boulos, M. K. \& Wheeler, S. (2007 in press). The emerging Web 2.0 social software: an enabling suite of sociable technologies in health and healthcare education. Health Informatics and Libraries Journal, 24.

Boulos, M. K., Maramba, I. \& Wheeler, S. (2006) Wikis, blogs and podcasts: a new generation of web-based tools for virtual collaborative clinical practice and education. BMC Medical Education, 6, 4. Retrieved June 16, 2007, from http://www.biomedcentral.com/1472-6920/6/41

de Freitas, S. (2006). Using games and simulations for supporting learning. Learning, Media and. Technology, 31, 343-358.

Deleuze, G. \& Guattari, F. (1987). A thousand plateaus: capitalism and schizophrenia. Minneapolis: University of Minnesota Press.

DfES (2006) 2020 Vision—Report of the Teaching and Learning in 2020 Review Group. Nottingham: DfES Publications.

Ebersbach, A., Glaser, M. \& Heigl, R. (2006). Wiki: web collaboration. Berlin: Springer-Verlag.

Gale, K. (2003). Creative pedagogies of resistance in post compulsory (teacher) education. In J. Satterthwaite, E. Atkinson \& K. Gale (Eds), Discourse, power resistance: challenging the rhetoric of contemporary education. Stoke: Trentham Books.

Godwin-Jones, R. (2003). Emerging technologies: blogs and wikis: environments for on-line collaboration. Language, Learning and Technology, 7, 12-16.

Harden, R. M. \& Crosby, J. R. (2000). The good teacher is more than a lecturer: the twelve roles of the teacher. Medical Teacher, 22, 334-347.

Horizon Report (2007). The Horizon Report 2007. Retrieved June 18, 2007, from http://www. nmc.org/pdf/2007_Horizon_Report.pdf]

Illich, I. (1970). Deschooling society. New York: Harper and Row.

Jacobs, J. (2003). Communication over exposure: the rise of blogs as a product of cybervoyeurism. Cited in J. B. Williams and J. Jacobs (2004), Exploring the use of blogs as learning spaces in the higher education sector. Australian Journal of Educational Technology, 20, 232-247.

Jonassen, D. H., Peck, K. L. \& Wilson, B. G. (1999) Learning with technology: a constructivist perspective. Upper Saddle River, NJ: Merrill.

Lave, J. \& Wenger, E. (1991). Situated learning: legitimate peripheral participation. Cambridge: Cambridge University Press.

Owen, M., Grant, L., Sayers, S. \& Facer, K. (2006) Opening education: social software and learning. Bristol: Futurelab. Retrieved November 20, 2006 from http://www.futurelab.org.uk/research

O'Reilly, T. (2004) Open source paradigm shift. Retrieved May 10, 2007, from http://tim. oreilly.com/articles/paradigmshift_0504.html]

Rheingold, H. (2003). Smart mobs: the next social revolution. Cambridge, MA: Perseus Books.

Richardson, W. (2006). Blogs, wikis, podcasts and other powerful web tools for classrooms. Thousand Oaks, CA: Corwin Press.

Stewart, T. (1996). The Invisible Key to Success. Fortune, 134, 173.

Terdiman, D. (2006). CNET news: study: Wikipedia as accurate as Britannica. Retrieved May 10, 2007, from http://news.com.com/2100-1038_3-5997332.html]

Wallace, P. (1999). The psychology of the internet. Cambridge: Cambridge University Press.

Wenger, E. (2000). Communities of practice. New York: Cambridge University Press.

Wheeler, S. (2001). Information and communication technologies and the changing role of the Teacher. Journal of Educational Media, 26, 7-18. 
Copyright of British Journal of Educational Technology is the property of Blackwell Publishing Limited and its content may not be copied or emailed to multiple sites or posted to a listserv without the copyright holder's express written permission. However, users may print, download, or email articles for individual use. 